\title{
Chylothorax and pleural effusion in contemporary extracardiac fenestrated fontan completion
}

\author{
Mauro Lo Rito, MD, ${ }^{\text {a }}$ Osman O. Al-Radi, MD, MSc, FRCSC, ${ }^{\mathrm{b}}$ Arezou Saedi, MD, \\ Yasuhiro Kotani, MD, PhD, ${ }^{\mathrm{d}}$ V. Ben Sivarajan, MD, MS, FRCPC, ${ }^{\mathrm{e}}$ Jennifer L. Russell, MD, FRCPC, \\ Christopher A. Caldarone, MD, ${ }^{c, g}$ Glen. S. Van Arsdell, MD, ${ }^{c, g}$ and Osami Honjo, MD, PhD ${ }^{c, g}$
}

\section{ABSTRACT}

Background: We hypothesized that chylothorax could be a sign of intolerance to the Fontan physiology, and thus patients who develop chylothorax or pleural effusion have worse medium-term to long-term survival.

Methods: A total of 324 patients who underwent the Fontan operation between 2000 and 2013 were included. Chylothorax was defined as $\geq 5 \mathrm{~mL} / \mathrm{kg} /$ day of chylomicron-positive chest drainage fluid no earlier than postoperative day 5 or drainage with $>80 \%$ lymphocytes. Outcomes were compared between the chylothorax and non-chylothorax groups by the Kaplan-Meier method and log-rank test. Independent predictors of chylothorax and number of days of any chest drainage were analyzed with multivariable logistic regression and multivariable generalized negative binomial regression for count data, respectively.

Results: Chylothorax occurred in 78 patients (24\%). Compared with the nonchylothorax group, the chylothorax group had a longer duration of chest tube requirement (median, 18 days vs 9 days; $P<.000$ ) and a longer length of hospital stay (median, 19 days vs 10 days; $P<.000)$. Eight patients $(10.3 \%$ ) required thoracic duct ligation. The chylothorax group had lower freedom from death $(P=.013)$ and from composite adverse events $(P=.021)$. No predictor was found for chylothorax. Pulmonary atresia $(P=.031)$ and pre-Fontan pulmonary artery pressure $(P=.01)$ were predictive of prolonged pleural effusion ( $>14$ days).

Conclusions: Occurrence of chylothorax following the Fontan operation can be a marker of poorer medium-term clinical outcomes. It is difficult to predict occurrence of chylothorax owing to its multifactorial nature and involvement of lymphatic compensatory capacity that is unmasked only after the Fontan operation. (J Thorac Cardiovasc Surg 2018;155:2069-77)

With incremental refinements of patient selection, surgical techniques, and perioperative management, the contemporary form of the Fontan operation for patients with a functional single-ventricle physiology is associated with

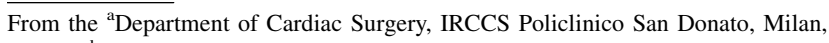
Italy; ${ }^{b}$ Department of Surgery, King Abdulaziz University, Jeddah, Saudi Arabia; Divisions of ${ }^{\mathrm{c} C a r d i o v a s c u l a r}$ Surgery and ${ }^{\mathrm{f} C}$ ardiology, Labatt Family Heart Centre, The Hospital for Sick Children, Toronto, Ontario, Canada; ${ }^{\mathrm{d}}$ Department of Cardio-

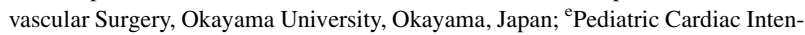
sive Care, Department of Pediatrics, Stollery Children's Hospital, Faculty of Medicine \& Dentistry, University of Alberta, Edmonton, Alberta, Canada; and ${ }^{\mathrm{g}}$ Department of Surgery, University of Toronto, Toronto, Ontario, Canada.

Received for publication Feb 24, 2017; revisions received Oct 27, 2017; accepted for publication Nov 11, 2017; available ahead of print Dec 15, 2017.

Address for reprints: Osami Honjo, MD, PhD, Division of Cardiovascular Surgery,

Labatt Family Heart Center, The Hospital for Sick Children, 555 University Ave,

Toronto, Ontario, Canada M5G1X8 (E-mail: osami.honjo@sickkids.ca). $0022-5223 / \$ 36.00$

Copyright (C) 2017 by The American Association for Thoracic Surgery

https://doi.org/10.1016/j.jtcvs.2017.11.046
}

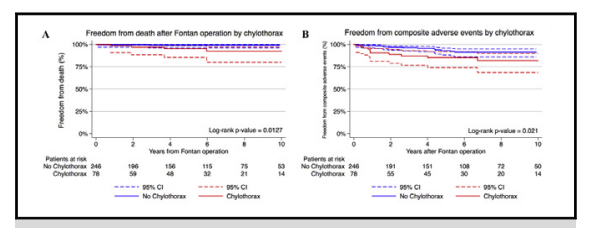

Kaplan-Meier curve showing lower freedom from composite adverse events in the chylothorax group.

\section{Central Message}

Chylothorax after the Fontan operation is a marker of intolerance to the Fontan circulation that is associated with poorer medium-term clinical outcomes.

\section{Perspective}

The occurrence of chylothorax following the Fontan operation can be a marker of poorer medium-term clinical outcomes. Patients with chylothorax are at increased risk of late death, protein-losing enteropathy, and plastic bronchitis. The occurrence of chylothorax is difficult to predict owing to its multifactorial nature and the involvement of lymphatic compensatory capacity that is unmasked only after the Fontan operation.

See Editorial Commentary page 2078.

See Editorial page 2067 excellent early survival. ${ }^{1,2}$ Nonetheless, redirection of the inferior vena cava to the pulmonary circulation in the context of the lack of a subpulmonary ventricle inevitably exposes the systemic venous and lymphatic system to substantially higher pressure, which is associated with the majority of the acute and late postoperative complications following Fontan completion.

Chylothorax and prolonged pleural effusion are common and important complications after Fontan completion. ${ }^{3,4}$ One of the proposed mechanisms of pleural effusion and

$\rightarrow$ Scanning this $\mathrm{QR}$ code will take you to a supplemental video for this article.

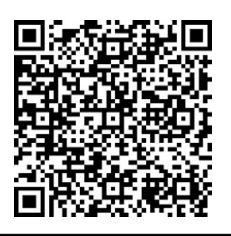




$$
\begin{aligned}
& \text { Abbreviations and Acronyms } \\
& \text { AV = atrioventricular } \\
& \text { IQR }=\text { interquartile range } \\
& \text { MCT }=\text { medium-chain triglycerides } \\
& \text { PA }=\text { pulmonary artery } \\
& \text { PLE }=\text { protein-losing enteropathy } \\
& \text { TPN }=\text { total parenteral nutrition }
\end{aligned}
$$

chylothorax in the Fontan physiology is the increase in hydrostatic capillary pressure, resulting in excessive filtration in the interstitial space and overwhelming drainage into the lymphatic system. ${ }^{5}$ A large multicenter study showed that chylothorax is associated with longer hospital stay, higher in-hospital mortality, and higher cost in children who underwent various types of congenital heart surgeries. ${ }^{6}$ In that study, the Fontan operation had the highest incidence of associated chylothorax, but a detailed subanalysis of the patients who underwent the Fontan operation was not performed. ${ }^{6}$

The primary aim of the present study was to identify predictors for chylothorax and prolonged pleural effusion in the contemporary Fontan cohort. We hypothesized that chylothorax may be a sign of intolerance to the Fontan physiology, and thus patients who develop chylothorax or pleural effusion have worse medium-term to long-term survival.

\section{METHODS}

This retrospective study included all patients who underwent the Fontan operation between 2000 and 2013 at The Hospital for Sick Children, Toronto. The hospital's Research Ethics Board approved the study and waived the need for patient consent. Patient demographic and preoperative characteristics are summarized in Tables 1 and 2.

\section{Criteria and Patient Selection}

Pre-Fontan cardiac catheterization is performed between 2 and 3 years of age to determine candidacy for Fontan completion. Standard criteria, including mean pulmonary artery (PA) pressure of $\leq 15 \mathrm{~mm} \mathrm{Hg}$, enddiastolic pressure of the systemic ventricle of $\leq 10 \mathrm{~mm} \mathrm{Hg}$, and the absence of important anatomic lesions, are used. Arteriopulmonary collaterals of significance are coil embolized at the pre-Fontan catheterization. Important anatomic lesions, such as atrioventricular (AV) valve regurgitation, aortic arch obstruction, or pulmonary vein stenosis, are typically addressed in an interim procedure, not as a concomitant procedure at the time of Fontan operation. Patients with elevated PA pressure and/or pulmonary vascular resistance are treated with a pulmonary vasodilator, typically sildenafil, and are reassessed with repeated cardiac catheterization after 3 to 6 months of treatment.

\section{Surgical Procedures}

The surgical technique has been described in detail elsewhere. ${ }^{7}$ In brief, an extracardiac Fontan operation using a polytetrafluoroethylene tube graft (typically 22 or $20 \mathrm{~mm}$ ) has been our standard approach throughout the study period. A 4-mm fenestration was routinely created unless technically difficult. A lateral tunnel Fontan was performed only when standard extracardiac Fontan operation was not feasible, typically in patients with isomerism hearts with unusual systemic and pulmonary venous arrangements. Procedures were done under normothermic or mild hypothermic cardiopulmonary bypass. Cardioplegic arrest was used only if concomitant intracardiac procedure was required. Modified ultrafiltration was routinely performed. Starting in the late 2000s, all patients were subjected to extubation in the operating room.

\section{Chylothorax: Definition and Treatment}

Our institutional diagnostic and treatment protocol has been outlined previously. ${ }^{8}$ In brief, pleural fluid in patients with persistent chest tube drainage $\geq 5 \mathrm{~mL} / \mathrm{kg} /$ day beyond postoperative day 5 is routinely tested for chylomicrons, lymphocyte fraction, and triglycerides. The presence of chylomicrons or a lymphocyte fraction $\geq 80 \%$ is defined as chylothorax. The medical treatment for confirmed chylothorax consists of 4 phases: phase 1, introduction of the medium-chain triglyceride (MCT) formula; phase 2, total parenteral nutrition (TPN) and nothing by mouth; phase 3 , prednisone administration ( $1 \mathrm{mg} / \mathrm{kg} / \mathrm{day})$; phase 4 , octreotide $(0.5-4 \mathrm{mg} /$ $\mathrm{kg} /$ hour intravenous continuous infusion). The duration of each phase is 5 to 7 days. Patients also undergo a vascular ultrasound to rule out occlusive thrombosis of the upper venous systems. The chylothorax is considered resolved and the chest tubes are removed once drainage is $\leq 2 \mathrm{~mL} / \mathrm{kg}$ / day for each individual drain, with the minimal fat diet continued for an additional 6 weeks after drain removal. If a patient does not respond to the first cycle of the treatment regimen, cardiac catheterization is performed to measure Fontan pressure, to rule out any anatomic issue, and to coil embolize any arteriopulmonary collaterals that potentially increases Fontan pressure. Thoracic duct ligation is considered when 2 cycles of medical treatment fail, and no anatomic lesions are detected on cardiac catheterization.

In this study, prolonged pleural effusion was defined as the need for a chest tube due to drainage of $>4 \mathrm{~mL} / \mathrm{kg} /$ day/tube for $>14$ days. Prolonged but nonchylous pleural effusion was treated with diuretics and fluid restriction, not with the chylothorax treatment regimen.

\section{Data Collection and Outcome Assessment}

All patients' clinical charts, echocardiography and cardiac catheterization reports, and operation records were reviewed. The Nakata index was calculated as the summation of the right and left PA cross-sectional areas indexed to the patient's body surface area. ${ }^{9}$ Qualitative assessments of ventricular function and degree of $\mathrm{AV}$ valve regurgitation were performed as described previously. ${ }^{10}$ Ventricular function was graded as normal, mildly reduced, moderately reduced, or severely reduced. The degree of AV valve regurgitation was graded as none/trivial, mild, moderate, or severe. Composite adverse events included death from any cause, transplantation, requirement for Fontan takedown, and development of protein-losing enteropathy (PLE) or plastic bronchitis.

\section{Statistical Analysis}

Continuous variables are summarized as median with interquartile range (IQR), and differences between groups were assessed with the Wilcoxon rank-sum test. Categorical and ordinal variables are presented as frequency and percentage, and differences were assessed with the $\chi^{2}$ or Fisher exact test according to group size. A $P$ value $<.05$ was considered significant. Independent predictors of chylothorax and the total number of days of any chest drainage were analyzed with multivariable logistic regression and multivariable generalized negative binomial regression for count data, respectively. The time-related freedom from death was assessed nonparametrically using the Kaplan-Meier method in patients otherwise censored at last known date to be alive or at the date of heart transplantation or Fontan takedown. Analyses were also conducted adjusted for age, body weight, and cardiopulmonary bypass time. All analyses were performed with $\mathrm{R}$ statistical packages ( $\mathrm{R}$ Institute for 
TABLE 1. Preoperative demographic data

\begin{tabular}{|c|c|c|c|c|}
\hline Preoperative variable & $\begin{array}{l}\text { All patients } \\
(\mathbf{n}=324)\end{array}$ & $\begin{array}{c}\text { Chylothorax group } \\
(n=78)\end{array}$ & No-chylothorax group $(n=246)$ & $P$ value \\
\hline Sex, males/females, $\mathrm{n}$ & $203 / 121$ & $48 / 30$ & $155 / 91$ & .815 \\
\hline \multicolumn{5}{|l|}{ Diagnosis, $\mathrm{n}(\%)$} \\
\hline Hypoplastic left heart syndrome & $75(23.1)$ & 21 (26.9) & $54(22)$ & .364 \\
\hline Tricuspid atresia & $70(21.6)$ & $15(19.2)$ & $55(22.4)$ & .559 \\
\hline Double-inlet left ventricle & $56(17.3)$ & $12(15.4)$ & 44 (17.9) & .611 \\
\hline Double-outlet right ventricle & $36(11.1)$ & $9(11.5)$ & $27(11)$ & .890 \\
\hline Isomerism & $25(7.7)$ & $7(9)$ & $18(7.3)$ & .633 \\
\hline Univentricular heart & $19(5.9)$ & $3(3.8)$ & $16(6.5)$ & $.581 *$ \\
\hline Pulmonary atresia & $15(4.6)$ & $3(3.8)$ & $12(4.9)$ & $1 *$ \\
\hline Atrioventricular septal defect & $12(3.7)$ & $5(6.4)$ & $7(2.8)$ & $.169 *$ \\
\hline 1-transposition & $11(3.4)$ & $1(1.3)$ & $10(4.1)$ & $.471^{*}$ \\
\hline d-transposition & $5(1.5)$ & $2(2.6)$ & $3(1.2)$ & $.597 *$ \\
\hline \multicolumn{5}{|l|}{ Dominant ventricle, $\mathrm{n}(\%)$} \\
\hline Left & $175(54)$ & $40(51.3)$ & $135(54.9)$ & .579 \\
\hline Right & $137(42.3)$ & 35 (44.9) & $102(41.5)$ & .595 \\
\hline Biventricular & $9(2.8)$ & $3(3.8)$ & $6(2.4)$ & $.454 *$ \\
\hline Undetermined & $3(0.9)$ & 0 & $3(1.2)$ & $1 *$ \\
\hline \multicolumn{5}{|l|}{ Ventricular function, $\mathrm{n}(\%)$} \\
\hline Normal & $310(95.7)$ & $75(96.2)$ & $235(95.5)$ & 1 \\
\hline Mildly reduced & $13(4)$ & $3(3.8)$ & $10(4.1)$ & $1 *$ \\
\hline Severely reduced & $1(0.3)$ & 0 & $1(0.4)$ & $1 *$ \\
\hline \multicolumn{5}{|c|}{ Atrioventricular valve regurgitation, $\mathrm{n}(\%)$} \\
\hline None to trivial & $178(54.9)$ & $38(48.7)$ & $140(56.9)$ & .205 \\
\hline Mild & $140(43.2)$ & $38(48.7)$ & $102(41.5)$ & .26 \\
\hline Moderate & $6(1.9)$ & $2(2.6)$ & $4(1.6)$ & $.633^{*}$ \\
\hline
\end{tabular}

$P$ values were calculated for the specific diagnosis versus all other diagnosis. Reported $P$ values were obtained with the $\chi^{2}$ test if not specified otherwise. ${ }^{*} P$ value obtained using the Fisher exact test.

Statistical Computing, Vienna, Austria) and Stata 12 (StataCorp, College Station, Tex).

\section{RESULTS (VIDEO 1) \\ Demographics}

A total of 324 patients underwent the Fontan operation during the study period. Hypoplastic left heart syndrome $(23 \% ; \mathrm{n}=75)$ and tricuspid atresia $(22 \% ; \mathrm{n}=70)$ were the most common diagnoses (Table 1). Preoperative ventricular function was normal in 310 patients $(95.7 \%)$, mildly reduced in 14 patients $(4.3 \%)$, and moderate to severely reduced in 1 patient. The majority of the patients had trivial or mild AV regurgitation, and 6 patients $(1.9 \%)$ had moderate regurgitation. Hemodynamic characteristics at pre-Fontan cardiac catheterization are shown in Table 2. The median PA pressure was $10 \mathrm{~mm} \mathrm{Hg}$ (IQR, 9$12 \mathrm{~mm} \mathrm{Hg}$ ), and median end-diastolic ventricular pressure was $7 \mathrm{~mm} \mathrm{Hg}$ (IQR, 5-8 mm Hg). The median Nakata index was $225.9 \mathrm{~mm}^{2} / \mathrm{m}^{2}\left(\mathrm{IQR}, 173-295 \mathrm{~mm}^{2} / \mathrm{m}^{2}\right)$. Collateral vessels were present in 170 patients $(52.5 \%)$ : aortopulmonary in $113(34.9 \%)$, venovenous in $38(11.7 \%)$, and both types in $19(5.9 \%)$. All but 1 patient with aortopulmonary collaterals underwent coil occlusion. Twenty-nine $(76.3 \%)$ venovenous collaterals were occluded.

\section{Operative Variables}

The Fontan operation was achieved with an extracardiac polytetrafluoroethylene graft in 294 patients $(90.7 \%)$ and with a lateral tunnel in 30 patients $(9.3 \%)$. A fenestration was created in 311 of the 324 patients $(96 \%)$. The median cardiopulmonary bypass time was 61 minutes (IQR, 4387 minutes). Cardioplegic cardiac arrest was required in 101 patients $(31.1 \%)$ for concomitant procedures, with a median aortic cross-clamp time of 30 minutes (IQR, 1952 minutes). Ninety-eight patients $(30.2 \%)$ were extubated in the operating room, and the remainder were extubated in the intensive care unit at a median time of 8 hours (IQR, 516 hours). The median lengths of intensive care unit and hospital stay are listed in Table 2.

\section{Mortality and Morbidity}

One in-hospital death occurred $(0.3 \%)$, due to progressive ventricular dysfunction and subsequent sepsis at 34 days after surgery. There were no acute deaths associated with chylothorax. There were 6 late deaths ( 5 in the chylothorax group and 1 in the non-chylothorax group) over the median follow-up period of 5.5 years (IQR, 2.6-9 years). All 5 patients in the chylothorax group had signs of failing 
TABLE 2. Preoperative hemodynamic, operative, and postoperative variables

\begin{tabular}{|c|c|c|c|c|}
\hline Variable & $\frac{\text { All patients }(\mathbf{n}=\mathbf{3 2 4})}{\text { Median }(\mathrm{IQR})}$ & $\frac{\text { Chylothorax group }(\mathbf{n}=\mathbf{7 8})}{\text { Median }(\mathrm{IQR})}$ & $\frac{\text { No chylothorax group }(n=246)}{\text { Median }(I Q R)}$ & $P$ value \\
\hline \multicolumn{5}{|l|}{ Preoperative hemodynamics } \\
\hline Nakata index, $\mathrm{mm}^{2} / \mathrm{m}^{2}$ & $226(174-295)$ & $244(192-302)$ & $221(171-288)$ & .132 \\
\hline Pulmonary artery pressure, $\mathrm{mm} \mathrm{Hg}$ & $10(9-12)$ & $10(9-11)$ & $10(9-12)$ & .805 \\
\hline Common atrial pressure, $\mathrm{mm} \mathrm{Hg}$ & $6(5-7)$ & $6(5-7)$ & $6(5-7)$ & .232 \\
\hline Systolic ventricular pressure, $\mathrm{mm} \mathrm{Hg}$ & $77(70-82)$ & $78(72-81)$ & $77(70-83)$ & .651 \\
\hline End-diastolic ventricular pressure, $\mathrm{mm} \mathrm{Hg}$ & $7(5-8)$ & $7(6-8)$ & $7(5-8)$ & .348 \\
\hline \multicolumn{5}{|l|}{ Operative } \\
\hline Age at surgery, y & $3.27(2.75-3.90)$ & $3.53(2.88-3.94)$ & $3.23(2.67-3.87)$ & .139 \\
\hline Body surface area, $\mathrm{m}^{2}$ & $0.56(0.52-0.60)$ & $0.55(0.51-0.59)$ & $0.56(0.52-0.61)$ & .084 \\
\hline Weight, kg & $13.7(12.5-15.5)$ & $13.5(12.2-15)$ & $14.1(12.6-15.8)$ & .058 \\
\hline Cardiopulmonary bypass time, min & $61(43-87)$ & $60(40-83)$ & $61(44-89)$ & .409 \\
\hline Aortic cross-clamp time, $\min ^{*}$ & $30(19-52)$ & $28(20-42)$ & $33(19-54)$ & .392 \\
\hline \multicolumn{5}{|l|}{ Postoperative } \\
\hline Hospital stay, d & $11(8-17)$ & $19(13-32)$ & $10(8-14)$ & .000 \\
\hline Chest drainage duration, $\mathrm{d}$ & $11(7-18)$ & $18(14-32)$ & $9(7-14)$ & .000 \\
\hline
\end{tabular}

$I Q R$, Interquartile range. *Aortic cross-clamp was used in 101 patients (no chylothorax group, $\mathrm{n}=74 ;$ chylothorax group, $\mathrm{n}=27$ ). The univariable $P$ value was calculated using the Wilcoxon rank-sum test.

Fontan physiology; death was due to consequences of plastic bronchitis in 2 patients, from intracardiac thrombosis and stroke in 1 patient, from significant Fontan failure and low output syndrome in 1 patient, and from complications following Fontan takedown in 1 patient. The late death in the non-chylothorax group was caused by PLE and subsequent respiratory failure.

In the entire cohort, freedom from death at 5 and 10 years after the Fontan operation was $98 \%$ and $97.4 \%$, respectively. Three patients required heart transplantation, including 2 patients for ventricular dysfunction, one at 5 months and the other at 4.7 years after the Fontan operation, and 1 patient for PLE at 7 years after the operation. None of these patients had chylothorax in the acute postoperative period. Twelve patients $(3.7 \%$; chylothorax group, $\mathrm{n}=5$; non-chylothorax group, $\mathrm{n}=7$ ) developed PLE. There

\section{Chylothorax and Pleural Effusion in Contemporary Extracardiac Fenestrated Fontan Completion}

\footnotetext{
Mauro Lo Rito MD, Osman O. Al-Radi MD, MSc, FRCSC, Arezou Saedi MD, Yasuhiro Kotani MD, PhD, V. Ben Sivarajan MD, MS, FRCPC, Jennifer L. Russell, MD, FRCPC, Christopher A. Caldarone MD, Glen. S. Van Arsdell MD, Osami Honjo MD PhD
}

The Labatt Family Heart Centre, The Hospital for Sick Children, Univeristy of Toronto, Toronto, Canada

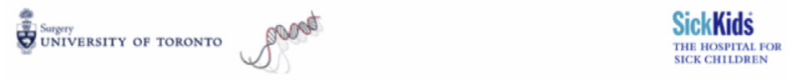

VIDEO 1. Discussion of relevant findings of chylothorax and pleural effusion. Video available at: http://www.jtcvsonline.org/article/S00225223(17)32732-0/fulltext. was no difference in freedom from PLE between the groups $(P=.126)$. Nine patients $(2.8 \%$; chylothorax, $\mathrm{n}=4$; nonchylothorax, $\mathrm{n}=5$ ) developed plastic bronchitis.

\section{Chylothorax}

Chylothorax occurred in 78 patients (24\%). Compared with the non-chylothorax group, the chylothorax group had a significantly longer duration of chest tube requirement (median, 18 days [IQR, 14-32 days] vs 9 days [IQR, 7-14 days]; $P<.0000)$ and longer length of hospital stay (median, 19 days vs 10 days; $P<.0000$ ). The majority $(\mathrm{n}=70 ; 89.7 \%)$ of the patients responded to medical treatment, whereas 8 patients $(10.3 \%)$ required thoracic duct ligation for refractory chylothorax. There was no mortality or morbidity associated with thoracic duct ligation procedures. There were no late deaths among the patients who underwent thoracic duct ligation. No patient required Fontan takedown due to persistent chylothorax. The chylothorax group had significantly lower freedom from death $(95 \%$ vs $99 \%$ at 5 years, $92 \%$ vs $99 \%$ at 10 years; $P=.013$ ) (Figure 1, $A$ ) and from composite adverse events $(85 \%$ vs $93 \%$ at 5 years, $81.8 \%$ vs $91.4 \%$ at 10 years; $P=.021$ ) (Figure 1, B). Adjusted analysis showed lower freedom from composite adverse events for the chylothorax group $(P=.025)$. There was no statistical difference in transplantation-free survival between the groups $(P=.140)$.

Comparisons of the chylothorax and non-chylothorax groups showed no differences in any preoperative or intraoperative variables (Tables 1 and 2). The sole trend seen was toward a relatively lower median body weight in the chylothorax group (13.5 kg vs $14.1 \mathrm{~kg} ; P=.058)$. Univariable and multivariable analyses did not identify any factors predictive of chylothorax (Table 3). In comparisons of 

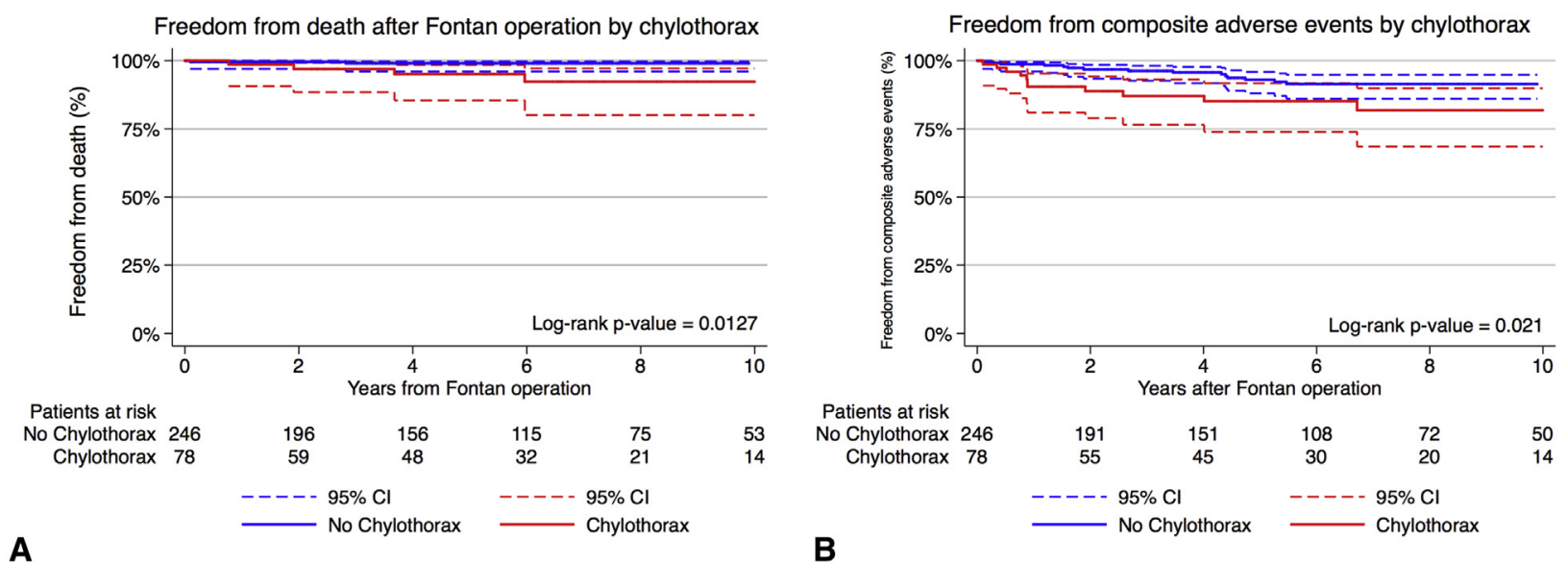

FIGURE 1. Freedom from death (A) and from composite adverse events (B) comparing the chylothorax group (red line) and the non-chylothorax group (blue line). Composite adverse events considered were death, heart transplant, Fontan takedown, protein-losing enteropathy, and plastic bronchitis. Dotted lines indicate $95 \%$ confidence interval $(C I)$.

patients with fenestration and without fenestration, the latter had a higher incidence of chylothorax $(22.6 \%$ vs $46.7 \% ; P=.033)$, although the number of patients without a fenestration was low in this cohort $(\mathrm{n}=13 ; 4 \%)$.

\section{Pleural Effusions and Chest Drainage Duration}

The median duration of pleural effusion, represented by the duration of chest tube requirement, was 10.5 days (IQR, 7-18 days). Although roughly one-third $(\mathrm{n}=111$; $34.2 \%$ ) of the patients had persistent pleural effusion ( $>14$ days), only one-half of those patients $(\mathrm{n}=56)$ had chylothorax. Diagnosis of pulmonary atresia $(P=.031)$ and pre-Fontan PA pressure were the predictors of prolonged pleural effusion $(P=.01)$. Pre-Fontan PA pressure and duration of chest tube requirement were highly correlated; each 5-mm Hg increment of the pre-Fontan PA pressure increased the duration of chest tube requirement by $25 \%$ (Figure 2). The presence of a fenestration decreased the duration of chest tube requirement by $27 \%(P=.04)$. Patients with prolonged nonchylous pleural effusion had comparable survival $(P=.354)$ and freedom from adverse events $(P=.814)$ as patients without prolonged nonchylous effusion (Figure 3).

\section{DISCUSSION}

The Fontan operation exposes the systemic venous and the lymphatic systems to a permanent nonphysiological high-pressure state. The acute pressure rise in these systems commonly results in prolonged pleural effusion and chylothorax, but the majority of patients adapt to the new physiology by the time of hospital discharge. In the present study we focused on chylothorax, rather than on prolonged pleural effusion in general, to delineate its incidence, preoperative predictors, and long-term implications. Our hypothesis was that chylothorax may be a sign of inability to handle the Fontan physiology, and thus those patients who had chylothorax in the acute postoperative period may have poorer clinical outcomes.

The most important findings of this study are the significantly lower freedom from death and from the composite adverse events in the patients with chylothorax compared with those without chylothorax. All late mortalities in the chylothorax group were related to the failing Fontan physiology, PLE, or plastic bronchitis. Our findings indicate that chylothorax not only prolonged the chest tube requirement, hospital length of stay, and costs, ${ }^{6}$ but also may be predictive of worse long-term outcomes. Among the patients with prolonged pleural effusion ( $>14$ days), only one-half had confirmed chylothorax. Furthermore, although preFontan PA pressure was strongly associated with the duration of chest tube requirement, it did not predict the occurrence of chylothorax. These findings suggest that chylothorax and prolonged nonchylous pleural effusion are 2 distinct phenomena that may have different mechanisms and long-term implications. None of the pre-Fontan anatomic and physiological parameters predicted chylothorax, which implies the involvement of lymphatic compensatory capacity and/or structural or functional lymphatic abnormalities as a part of the mechanisms of chylothorax that might not be recognizable before Fontan completion.

\section{Mechanisms of Post-Fontan Chylothorax}

Increase in systemic venous pressure as a result of Fontan completion inevitably causes systemic venous congestion, which impedes effective drainage of the lymphatic system. Furthermore, increased systemic venous pressure causes significant increases in lymph production, mainly from the liver. ${ }^{11}$ Among adults with decompensated congestive heart failure, thoracic ductal lymph flow and pressure are 
TABLE 3. Preoperative risk factors for chylothorax

\begin{tabular}{|c|c|c|c|c|}
\hline \multirow[b]{2}{*}{ Variable } & \multicolumn{2}{|c|}{ Univariable } & \multicolumn{2}{|c|}{ Multivariate } \\
\hline & OR & $\overline{P \text { value }}$ & OR & $P$ value \\
\hline Sex & 1.065 & .815 & & \\
\hline Hypoplastic left heart syndrome & 1.310 & .365 & 0.396 & .382 \\
\hline Tricuspid atresia & 0.827 & .559 & 0.264 & .236 \\
\hline Double-inlet left ventricle & 0.835 & .611 & 0.244 & .213 \\
\hline Double-outlet right ventricle & 1.058 & .890 & 0.354 & .346 \\
\hline Isomerism & 1.249 & .633 & 0.446 & .475 \\
\hline Univentricular heart & 0.575 & .389 & 0.202 & .189 \\
\hline Pulmonary atresia & 0.780 & .706 & 0.295 & .338 \\
\hline Atrioventricular septal defect & 2.339 & .157 & 0.721 & .785 \\
\hline 1-transposition & 0.306 & .263 & 0.099 & .129 \\
\hline d-transposition & 2.132 & .412 & & \\
\hline Dominant ventricle & 1.123 & .545 & 0.872 & .662 \\
\hline Ventricular function & 0.781 & .667 & 0.783 & .683 \\
\hline Atrioventricular valve regurgitation & 1.205 & .236 & 1.087 & .66 \\
\hline Age $(y)$ & 0.987 & .865 & 0.932 & .436 \\
\hline Body surface area $\left(\mathrm{m}^{2}\right)$ & 0.305 & .336 & & \\
\hline Weight (kg) & 0.941 & .149 & & \\
\hline Nakata index $\left(\mathrm{mm}^{2} / \mathrm{m}^{2}\right)$ & 1.001 & .254 & 1.002 & .196 \\
\hline Cavopulmonary pressure $(\mathrm{mm} \mathrm{Hg})$ & 1.003 & .968 & 0.937 & .468 \\
\hline Common atrial pressure $(\mathrm{mm} \mathrm{Hg})$ & 1.089 & .211 & 1.052 & .562 \\
\hline Systolic ventricular pressure $(\mathrm{mm} \mathrm{Hg})$ & 1.004 & .772 & 1.006 & .656 \\
\hline End-diastolic ventricular pressure $(\mathrm{mm} \mathrm{Hg})$ & 1.058 & .290 & 1.045 & .499 \\
\hline
\end{tabular}

$O R$, Odds ratio.

increased by as much as 7 -fold and 3 -fold, respectively. ${ }^{11}$

The double burden of increased lymph production in the system in which drainage is already impeded by higher systemic venous pressure is likely one of the main mechanisms of chylothorax. That being said, the majority of the patients $(>75 \%)$ in our cohort did not have chylothorax

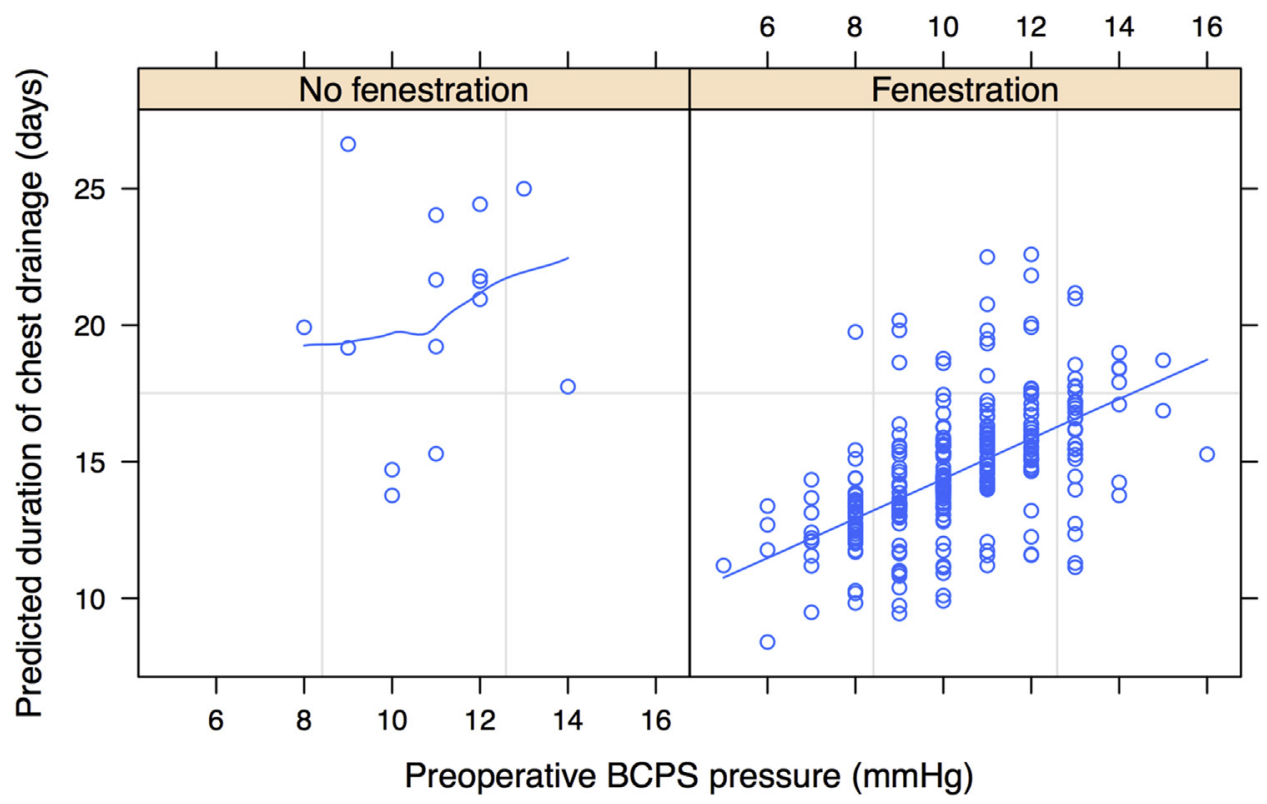

FIGURE 2. Correlation between pre-Fontan bidirectional cavopulmonary pressure (BCPS) and duration of chest tube requirement in nonfenestrated (left) and fenestrated (right) Fontan patients. 

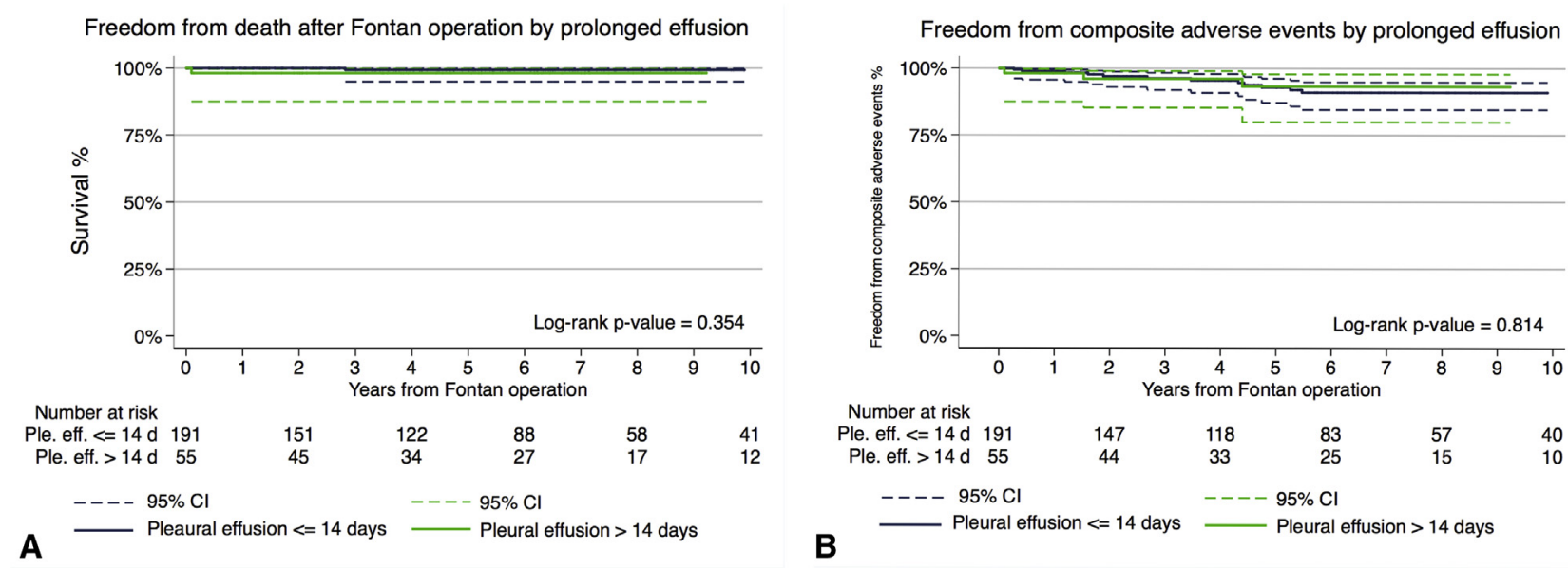

FIGURE 3. Freedom from death (A) and from composite adverse events (B) comparing patients with prolonged (>14 days) nonchylous pleural effusion (green line) without prolonged nonchylous pleural effusions (dark-blue line). Composite adverse events considered were death, heart transplant, Fontan take-down, protein-losing enteropathy, and plastic bronchitis. Dotted lines indicate $95 \%$ confidence interval (CI). Patients with prolonged nonchylous pleural effusion and those without prolonged nonchylous effusion have comparable survival ( $98 \%$ vs $99 \%$ at 5 and 10 years; $P=.354)$ and freedom from composite adverse events ( $93 \%$ vs $93 \%$ at 5 years; $93 \%$ vs $91 \%$ at 10 years; $P=.814$ ). Ple. eff., Pleural effusion.

despite the increased systemic venous pressure. An adult sheep study showed that thoracic ductal lymph flow rate is maintained against relatively high systemic venous pressure, with an inverse linear correlation between systemic venous pressure and lymph flow rate. ${ }^{12}$ At least $50 \%$ to $75 \%$ of the lymph flow is maintained at a systemic venous pressure $<15 \mathrm{~mm} \mathrm{Hg}$. Those findings imply the involvement of other factors in the development of chylothorax.

An important study by Dori and colleagues ${ }^{13}$ showed evidence of significant lymphatic anatomic abnormalities, including thoracic duct dilatation, lymphangiectasis, and lymphatic collateralization in patients with Fontan circulation, especially in those with PLE or plastic bronchitis. ${ }^{13}$ Three major factors in the lymphatic system-congestion, increased production, and structural or functional abnormalities - contribute to the development of chylothorax in the Fontan population. Therefore, unlike nonchylous plural effusion, which has a linear relationship with pre-Fontan PA pressure, chylothorax is very difficult to predict until completion of the Fontan operation. Clinically important chylothorax may be a marker of poor long-term outcomes, demonstrating an inability to handle overwhelming lymphatic congestion and increased production, which may or may not improve over time. Exploration of functional imaging of the thoracic duct, including its flow characteristics, using magnetic resonance imaging may provide insight into its mechanism and potential therapy. ${ }^{14}$

\section{Long-Term Implications of Chylothorax}

This study clearly shows that patients who experience chylothorax in the acute postoperative period are at higher risk of late death and adverse events, such as PLE and plastic bronchitis. All 5 late deaths in our cohort were associated with failing Fontan physiology, PLE, or plastic bronchitis. Schumacher and colleagues ${ }^{15}$ reported a similar trend toward a higher incidence of chylothorax among patients who subsequently developed PLE or plastic bronchitis. Considering the vulnerability of the lymphatic system to high systemic venous pressure in patients with chylothorax, it is conceivable that these lymphatic systems tend to readily decompensate with even subtle increases in Fontan pressure compared with patients who have greater compensatory capacity. Given the poor prognosis of patients with PLE and plastic bronchitis, ${ }^{16,17}$ early Fontan takedown or listing for transplantation may be a wise decision for patients showing signs of repeated lymphatic decompensation, such as initial chylothorax followed by PLE or plastic bronchitis, and intolerance to the Fontan circulation.

\section{Predictors of Chylothorax and Prolonged Pleural Effusion}

Pre-Fontan PA pressure was found to be a predictor for duration of chest tube requirement. A 5-mm $\mathrm{Hg}$ increment in pre-Fontan PA pressure was associated with a $25 \%$ increase in the duration of chest tube requirement (Figure 2). This phenomenon is much easier to explain as the degree of capillary leak corresponding to Fontan pressure. Diagnosis of pulmonary atresia was also found to be predictive of a prolonged chest tube requirement. The patients with pulmonary atresia in this cohort did not necessarily have high PA pressure or a low Nakata index at preFontan assessment, and thus the association between this specific diagnosis and prolonged pleural effusion is not clear. There was absolutely no pre-Fontan predictor for 
chylothorax as outlined above. Like patients who require a persistent fenestration late after the Fontan operation even though pre-Fontan numbers were reasonable, ${ }^{7}$ the occurrence of chylothorax is a reaction of the lymphatic system to the Fontan circulation, which is unmasked only after the Fontan operation.

\section{Medical and Surgical Management of Chylothorax}

Medical treatment for chylothorax varies widely. ${ }^{6,18}$ The patients our cohort were treated following our institutional treatment algorithm. ${ }^{8}$ Our medical regimen includes MCT formula, TPN, prednisone, and octreotide, as commonly used in other institutions as well. In a study of practice patterns in medical treatment of chylothorax among 43 pediatric hospitals across the United States, Mery and colleagues ${ }^{6}$ identified TPN as the most widely used $(56 \%)$, followed by octreotide (16\%) and MCT formula (1.7\%; likely underreported). Prednisone is not commonly used for treating chylothorax, ${ }^{6,18}$ although some patients have demonstrated a good response to prednisone treatment. Panthongviriyakul and colleagues ${ }^{18}$ suggested a new treatment algorithm for chylothorax that initially triages patients based on central venous pressure $(15 \mathrm{~mm} \mathrm{Hg}$ as a cutoff value), followed by medical treatment similar to that specified in our algorithm, except for the use of corticosteroids. In our cohort, 8 patients $(10.3 \%)$ required thoracic duct ligation for refractory chylothorax. The procedure was effective in all cases, without morbidity or mortality. Although a minority of patients exhibit a dramatic response to medical therapy, in most cases chylothorax improves over time, which may be the most important factor in its resolution.

\section{Incidence of Chylothorax}

The incidence of chylothorax in this series is higher that reported in previous studies, ${ }^{6,19}$ including one published by our group. ${ }^{8}$ The increasing incidence of chylothorax, from $11.5 \%$ to $24 \%$, in the last decade can be explained by the introduction of routine testing for chylomicrons and lymphocyte counts in the early 2000s. ${ }^{8}$ Patients with chest fluid drainage exceeding $5 \mathrm{~mL} / \mathrm{kg} /$ day at postoperative day 5 are routinely tested for chylothorax even if the drainage fluid is not milky, to help guide the therapeutic strategy. Highoutput nonchylous pleural effusion is managed with fluid restriction and diuretics without the chylothorax treatment regimen. On the other hand, any patient diagnosed with chylothorax is treated with the treatment regimen whenever drainage exceeds $2 \mathrm{~mL} / \mathrm{kg} /$ day. This institutional diagnostic and treatment strategy for chylothorax is likely the reason for the higher chylothorax rate reported in our present series.

\section{Fenestration and Chylothorax}

Our data show a significantly higher $(46.7 \%)$ incidence of chylothorax in the nonfenestration group, even though this group represents only $4 \%$ of our cohort owing to institutional bias. Our data also show that creation of a fenestration decreased the duration of chest tube requirement by a median of $27 \%$, which is consistent with findings of most previous series. ${ }^{20}$ Atz and colleagues ${ }^{3}$ reported a large clinical series from the Pediatric Heart Network showing a significantly lower incidence of morbid pleural effusion among the patients with a fenestration. The authors did not conduct a separate analysis of the incidence of chylothorax in the 2 groups, however. Salazer and colleagues ${ }^{21}$ reported their experience with nonfenestrated Fontan completion showing a comparable duration of chest tube requirement in the fenestration and nonfenestration groups. It is conceivable that fenestration reduces chylothorax by lowering Fontan pressure and subsequent lymphatic congestion; however, our data should be interpreted with care given the small number of nonfenestrated patients in this series. Whether fenestration reduces the risk of lymphatic system-related complications in patients with marginal lymphatic compensatory capacity would be an interesting avenue of research.

\section{Study Limitations}

One limitation of this study is its single-center retrospective design. Given the very low rates of adverse events such as death, PLE, and plastic bronchitis, a larger patient population would have been preferable. Episodes of chylothorax or prolonged pleural effusion in the first and second singleventricle palliations, potential predictors of subsequent chylothorax; were not captured. Finally, our analysis of the effect of fenestration on chylothorax must be interpreted with caution, given the small number of nonfenestrated patients in our cohort.

\section{CONCLUSIONS}

Chylothorax following the Fontan operation can be a marker of poorer medium-term outcomes. Unlike nonchylous pleural effusion, chylothorax is difficult to predict owing to its multifactorial nature and involvement of lymphatic compensatory capacity that is unmasked only after Fontan operation. Patients with repeated episodes of intolerance to the Fontan circulation may be better triaged to early Fontan takedown or listing for transplantation. Future research to delineate structural and functional characteristics of the lymphatic system may provide insight into new therapeutic targets.

\section{Conflict of Interest Statement}

Authors have nothing to disclose with regard to commercial support.

We thank Bushra Momtaz for assisting with data collection, and Kathleen Einarson and Leah Costa for supporting the chylothorax clinical program. 


\section{References}

1. Rogers LS, Glatz AC, Ravishankar C, Spray TL, Nicolson SC, Rychik J, et al. 18 years of the Fontan operation at a single institution: results from 771 consecutive patients. J Am Coll Cardiol. 2012;60:1018-25.

2. d'Udekem Y, Iyengar AJ, Galati JC, Forsdick V, Weintraub RG, Wheaton GR, et al. Redefining expectations of long-term survival after the Fontan procedure: twenty-five years of follow-up from the entire population of Australia and New Zealand. Circulation. 2014;130(11 Suppl 1):S32-8.

3. Atz AM, Travison TG, McCrindle BW, Mahony L, Quartermain M, Williams RV, et al. Late status of Fontan patients with persistent surgical fenestration. J Am Coll Cardiol. 2011;57:2437-43.

4. Iyengar AJ, Winlaw DS, Galati JC, Celermajer DS, Wheaton GR, Gentles TL, et al. Trends in Fontan surgery and risk factors for early adverse outcomes after Fontan surgery: the Australia and New Zealand Fontan registry experience. $J$ Thorac Cardiovasc Surg. 2014;148:566-75.

5. Buchhorn R, Bartmus D, Buhre W, Bürsch J. Pathogenetic mechanisms of venous congestion after the Fontan procedure. Cardiol Young. 2001;11:161-8.

6. Mery CM, Moffett BS, Khan MS, Zhang W, Guzmán-Pruneda FA, Fraser CD Jr, et al. Incidence and treatment of chylothorax after cardiac surgery in children: analysis of a large multi-institution database. J Thorac Cardiovasc Surg. 2014; 147:678-86.e1; discussion 685-6.

7. Kotani Y, Chetan D, Saedi A, Zhu J, Grosse-Wortmann L, Coles JG, et al. Persistent fenestration may be a marker for physiologic intolerance after Fontan completion. J Thorac Cardiovasc Surg. 2014;148:2532-8.

8. Chan EH, Russell JL, Williams WG, Van Arsdell GS, Coles JG, McCrindle BW. Postoperative chylothorax after cardiothoracic surgery in children. Ann Thorac Surg. 2005;80:1864-70.

9. Nakata S, Imai Y, Takanashi Y, Kurosawa H, Tezuka K, Nakazawa M, et al. A new method for the quantitative standardization of cross-sectional areas of the pulmonary arteries in congenital heart diseases with decreased pulmonary blood flow. J Thorac Cardiovasc Surg. 1984;88:610-9.

10. Honjo O, Atlin CR, Mertens L, Al-Radi OO, Redington AN, Caldarone CA, et al. Atrioventricular valve repair in patients with functional single-ventricle physiology: impact of ventricular and valve function and morphology on survival and reintervention. J Thorac Cardiovasc Surg. 2011;142:326-35.e2.
11. Witte MH, Dumont AE, Clauss RH, Rader B, Levine N, Breed ES. Lymph circulation in congestive heart failure: effect of external thoracic duct drainage. Circulation. 1969;39:723-33.

12. Brace RA, Valenzuela GJ. Effects of outflow pressure and vascular volume loading on thoracic duct lymph flow in adult sheep. Am J Physiol. 1990;258(1 Pt 2):R240-4.

13. Dori Y, Keller MS, Fogel MA, Rome JJ, Whitehead KK, Harris MA, et al. MRI of lymphatic abnormalities after functional single-ventricle palliation surgery. AJR Am J Roentgenol. 2014;203:426-31.

14. Dori Y, Keller MS, Rychik J, Itkin M. Successful treatment of plastic bronchitis by selective lymphatic embolization in a Fontan patient. Pediatrics. 2014;134:e590-5.

15. Schumacher KR, Stringer KA, Donohue JE, Yu S, Shaver A, Caruthers RL, et al Fontan-associated protein-losing enteropathy and plastic bronchitis. J Pediatr. 2015;166:970-7.

16. Mertens L, Hagler DJ, Sauer U, Somerville J, Gewillig M. Protein-losing enter opathy after the Fontan operation: an international multicenter study. PLE study group. J Thorac Cardiovasc Surg. 1998;115:1063-73.

17. Costello JM, Steinhorn D, McColley S, Gerber ME, Kumar SP. Treatment of plastic bronchitis in a Fontan patient with tissue plasminogen activator: a case report and review of the literature. Pediatrics. 2002;109:e67.

18. Panthongviriyakul C, Bines JE. Post-operative chylothorax in children: an evidence-based management algorithm. J Paediatr Child Health. 2008;44:716-21.

19. Mavroudis C, Mavroudis CD, Jacobs JP, Siegel A, Pasquali SK, Hill KD, et al Procedure-based complications to guide informed consent: analysis of Society of Thoracic Surgeons congenital heart surgery database. Ann Thorac Surg. 2014;97:1838-49; discussion 1849-51.

20. Lemler MS, Scott WA, Leonard SR, Stromberg D, Ramaciotti C. Fenestration improves clinical outcome of the Fontan procedure: a prospective, randomized study. Circulation. 2002;105:207-12.

21. Salazar JD, Zafar F, Siddiqui K, Coleman RD, Morales DL, Heinle JS, et al Fenestration during Fontan palliation: now the exception instead of the rule. J Thorac Cardiovasc Surg. 2010;140:129-36.

Key Words: chylothorax, Fontan, pleural effusion, predictors 